\title{
A cronística de Rubem Braga em livro didático: Notas sobre o processo transmissão da crônica Ela tem alma de pomba
}

\section{The chronicle writings of Rubem Braga in the textbook: Notes on the conveyance process of the chronicle She has a dove soul}

\author{
Bárbara Bezerra de Santana Pereira* \\ Universidade do Estado da Babia \\ Jacobina, Bahia, Brasil \\ Manoel Mourivaldo Santiago Almeida** \\ Universidade de São Paulo \\ São Paulo, São Paulo, Brasil
}

\begin{abstract}
Resumo: Este artigo tem por principal objetivo realizar uma breve análise do processo de transmissão, em Livro Didático, da crônica "Ela tem alma de pomba", do escritor capixaba Rubem Braga. Inicialmente, trazemos um apanhado acerca do gênero textual com as particularidades e complexidades que lhe são inerentes, posteriormente, verticalizamos para as crônicas rubembraguianas e a presença dessas em materiais didáticos. A partir do cotejo de três tipos de testemunhos, apresentamos um exemplo de análise, pelo prisma da Filologia, utilizando a transcrição encontrada num Livro Didático de Língua Portuguesa, do $6^{\circ}$ ano do Ensino Fundamental, do ano de 1998.
\end{abstract}

Palavras-Chave: Filologia. Crônica. Rubem Braga. Livro Didático

\begin{abstract}
The present article has as its main goal to analyse the process of conveyance, in the Textbook, of the chronicle "She has a dove soul", by the writer Rubem Braga, from Espírito Santo. The article presented here brings a summary of the genre chronicle with the particularities and complexities that are inherent to it, afterwards, we verticalized of the rubembraguian chronicles and the presence of those in the textbooks. From the collection of three kinds of testimonies, we presented an example of analysis, in the light of Philology, using the transcription found in a Portuguese Language Textbook, of the 6th year of Elementary School, of the year 1998.
\end{abstract}

Keywords: Philology. Chronicle. Rubem Braga. Textbook.

\footnotetext{
* Doutoranda pelo Programa de Pós- Graduação em Filologia e Língua Portuguesa da USP. Professora Assistente da área de Filologia Românica do DCH IV Jacobina- UNEB. E-mail: baletras02@hotmail.com. ** Doutor em Filologia e Língua Portuguesa e Livre Docência em Fonética e Fonologia do Português na Universidade de São Paulo. Pós-Doutorado em Crítica Textual na Universidade Federal de Minas Gerai. Bolsista de produtividade em pesquisa do CNPq desde 2011 e consultor/parecerista do CNPq, CAPES, FAPESP, Editoras e Revistas Científicas. É professor titular da Universidade de São Paulo. E-mail: msantiago@usp.br.
} 


\section{INTRODUÇÃO}

Gênero ambíguo e rico em interpretações e análises, a crônica aparece frequentemente em Livros Didáticos de diversas séries, principalmente nas do segundo ciclo do Ensino Fundamental. Ao tratarmos desse gênero textual na literatura brasileira moderna, a obra de Rubem Braga desponta como principal destaque. Braga não se fez, nem se faz presente apenas em jornais, revistas e livros, mas também nas páginas de diversos livros didáticos, desde a década de 1960.

O texto que ora se apresenta traz, através da ótica filológica, uma breve e inicial análise da crônica "Ela tem alma de pomba", encontrada num livro didático do ano de 1998. Para tanto, realizamos e apresentamos o cotejo entre três tipos de testemunhos, a saber, Texto Didático (doravante TD), Texto Base (doravante TB) e Texto Indicado como Referência (doravante TIR). A partir da comparação, tecemos breves comentários sobre algumas variantes encontradas.

Para contextualizar a análise, apresentamos inicialmente aspectos conceituais acerca do gênero textual crônica, bem como as características do estilo de escrita rubembraguiano. Vale destacar que a presente pesquisa encontra-se em curso, sendo assim, objetivamos apenas levantar discussões acerca da realidade editorial didática, sem conclusões definitivas.

\section{ENTRE O PERENE E O TRANSITÓRIO: CARACTERÍSTICAS DA CRÔNICA MODERNA}

Caracterizar um gênero como a crônica não é tarefa fácil. Apesar de uma aparente simplicidade no que tange ao tema e à linguagem, sua complexidade e variabilidade (crônicas líricas, ficcionais, narrativas, metafísicas) se destacam. Defini-la ou conceituá-la torna-se um árduo intento, pois, fatalmente, faltarão ou sobrarão aspectos que se encaixarão em alguns espécimes e em outros não. Não há uma receita mas, de forma panorâmica, podemos afirmar que a crônica apresenta o cotidiano como tema, o diálogo com o leitor e a linguagem fluente direcionada ao coloquial/oral como estilo e a liberdade como principal pressuposto. Uma "radical liberdade", como colocado por Castelo (2007). Liberdade essa que dificulta sua definição, como também colocado por Bender (1993, p. 44) na citação que segue

E a liberdade é uma das principais características da crônica. Daria para dizer-se o que não dá crônica, principalmente pela limitação do espaço: tem-se de preencher aquela coluna e só. Já não se poderia especificar qual é a matéria-prima do gênero, por ser a própria vida. A vida como ela é ou não é, as aventuras ou desventuras do cotidiano, as notícias de hoje, de ontem, da infância ou mesmo aquelas que nunca foram notícias. Não há restrição de assunto para a crônica, talvez para compensar o pouco espaço. E essa total liberdade, também quanto à estrutura, faz ser difícil a sua conceituação. (BENDER, 1993, p. 44).

Por ser livre e ter a vida como principal assunto, a crônica apresenta-se simples e complexa, como a própria vida, sua matéria-prima. Vida e tempo são termos e essências que se entremeiam nas linhas da crônica.

As principais características desse gênero estão ligadas ao conceito de tempo, relação do termo desde sua gênese etimológica. Essa relação com o tempo denota, além do registro do momento, uma urgência de produção e recepção. Por ser um texto originariamente do veículo jornalístico, a crônica tende a assimilar características como transitoriedade e efemeridade, 
próprias dos textos veiculados nesse tipo de suporte. Urgência, seja para escrever como para ler, propicia o desenvolvimento de uma escrita aparentemente simples e coloquial. Com a palavra Sá (1992, p. 10):

A aparência de simplicidade, portanto, não quer dizer desconhecimento das artimanhas artísticas. Ela decorre do fato de que a crônica surge primeiro no jornal, herdando sua precariedade, esse seu lado efêmero de quem nasce no começo de uma leitura e morre antes que se acabe o dia, no instante em que o leitor transforma as páginas em papel de embrulho, ou guarda os recortes que mais lhe interessam num arquivo pessoal.

Consequentemente, esse duelo com o tempo, proporciona e desenvolve uma linguagem mais acessível ao público, coloquial, próxima da oralidade, de forma dialogada entre o escritor e leitor. Como destacado por Antonio Cândido, em seu clássico texto $A$ vida ao rés-do-chão, "Por meio dos assuntos, da composição aparentemente solta, do ar de coisa sem necessidade que costuma assumir, ela se ajusta à sensibilidade de todo dia. Principalmente porque elabora uma linguagem que fala de perto ao nosso de ser mais natural." (CÂNDIDO, 1992, p. 13)

O cronista, a partir de algum acontecimento banal ou da falta de um assunto (tema muito recorrente entre os autores do gênero), transcende a análise do acontecimento em si para realizar uma reflexão universal e, ao mesmo tempo, aprofundada, sem o peso de reflexões profundas. Relatar sua revolta e/ou opinião sobre algo, alguém, ou simplesmente, rir e nos fazer rir de nós mesmos.

Com o seu toque de lirismo reflexivo, o cronista capta esse instante brevíssimo que também faz parte da condição humana e lhe confere (ou lhe devolve) a dignidade de um núcleo estruturante de outros núcleos, transformando a simples situação no diálogo sobre a complexidade das nossas dores e alegrias. (SÁ, 1992, p. 11)

Para ressaltar um pouco mais os paradoxos que permeiam o conceito desse gênero, tais como, sua simplicidade e complexidade, sua efemeridade e perenidade, retomemos a discussão acerca do lugar da crônica. Depois de sua fase inicial, voltada ao relato histórico, ela (re)surge e se desenvolve em jornais. A presença da crônica em veículos como jornais e revistas, sua fixação como texto literário e a consequente presença em livros, torna a análise do gênero ainda mais vasta e complexa. Por encontra-se no limiar entre o texto literário e jornalístico, esse gênero é considerado híbrido, ambíguo, anfíbio. Seu habitat natural é o jornal, revistas, veículos de comunicação de acesso rápido e de conteúdo volátil, mas com o tempo e por conta sua natureza, de sua latente literariedade, ganha espaço e eternização nas páginas de livros. Sobre essa questão muito já foi discutido, haja vista as previsões de Massaud Moisés sobre a presença da crônica em livro e seu fim:

A crônica destina-se ao consumo diário, como nenhuma outra obra que se pretenda literária. Fugaz como o jornal e a revista, mal resiste ao livro: quando um escritor se decide a perpetuar os textos que espalhou no dia-a-dia jornalístico, inevitavelmente seleciona aqueles que sua autocrítica e a alheia the sugere como os aptos a enfrentar o desafio do tempo. E por mais exigente que seja seu paladar ou aguda percepção de valores, as crônicas eleitas geralmente perdem, cedo ou tarde, a batalha contra o envelhecimento. A própria instituição livro, não sendo sua morada permanente, mas a eventual, parece um ataúde, florido e pomposo, mas ataúde (MOISÉS, 1982, p.119) 
A previsão de Moisés (1982), até o momento, não se confirmou haja vista as constantes reedições das obras de vários cronistas, principalmente as de Rubem Braga (como exemplo o 200 crônicas escolbidas, um dos mais vendidos, o qual compila textos dos anos de 1935 a 1977, que já se aproxima de sua quadragésima edição, além de edições comemorativas). Braga, na crônica "Manisfesto", compara a produção de um texto em livro com a construção de uma casa e a de uma crônica em jornal com a armação de uma tenda de cigano. "Nossos edifícios são bem diversos. Há homens que são escritores e fazem livros que são verdadeiras casas, e ficam. Mas o cronista é como o cigano que toda noite arma sua tenda e pela manhã a desmancha, e vai." (BRAGA, 1988, p. 153). A partir dessa comparação, Sá (1992, p. 17) faz a devida ressalva da crônica em livro,

Ora, o cronista de jornal também é um escritor, e também ele deseja escrever algo que fique para sempre. A crônica, portanto, é uma tenda de cigano enquanto consciência da sua transitoriedade; no entanto é casa - e bem sólida até - quando reunida em livro, onde se percebe com maior nitidez a busca de coerência no traçado da vida, a fim de torná-la mais gratificante e, somente assim, mais perene.

No entanto, nem todas as crônicas veiculadas em jornais são adequadas às páginas de livros, por mais gabaritado que seja o autor ${ }^{1}$, o valor artístico dos textos pode variar, sendo necessária a devida escolha das crônicas que "morarão" nos livros. Sobre essa escolha, voltamos ao livro 200 crônicas escolbidas, de Rubem Braga, que traz uma nota explicativa do autor informando que os textos presentes no livro teriam sido inicialmente escolhidos por Fernando Sabino e que Braga teria feito algumas trocas "levado por algum motivo, às vezes sentimental." Sá (1992, p.19) esclarece que as escolhas de Braga passavam pelo crivo da análise temporal, eliminando as que ele considerava datadas e situacionais e "[...] agrupando na coletânea aquelas que conservam o seu poder de provocar a nossa reflexão". Reverbel (2002) traz outro exemplo que atesta o nível de exigência que Braga tinha ao escolher suas crônicas para publicação em livro. Quando publicou seu primeiro livro, $O$ conde e o passarinho, Braga escolheu 28 crônicas das 2000 que até então havia escrito para jornais.

Luis Carlos Santos Simon, no artigo O cotidiano encadernado: a crônica no livro, publicado nos anais do I Seminário Brasileiro sobre o Livro e História Editorial, 2004, ressalta as querelas acerca dessa transferência de suporte e a realidade editorial do livro de crônicas, concluindo que

Parece ter ficado claro que o mercado editorial, há vinte ou trinta anos, tem acreditado mais na viabilidade da publicação de livros de crônicas. Mais do que isso, recentemente pode-se

\footnotetext{
${ }^{1}$ José Aderaldo Castello (1964, p. 145-146) faz essa ressalva ao observar que "Há crônicas, assim, que resultam de uma abordagem superficial e rápida de fatores exteriores, flagrantes de vida, detalhes que se acumulam conforme o ponto de vista selecionador em que se coloca o observador na paisagem destacada, que seu espírito criador eleva à condição de ambiência condicionadora. Mesmo assim, o valor artístico é reduzido, não conseguindo o cronista fugir à sedução fácil do registro comovedor e confortador, naturalmente em face das desigualdades sociais e humanas, acentuando contrastes, injustiças, equívocos, etc., pensando, evidentemente no leitor comum ou dando graças a Deus de ter cumprido o seu dever de cronista."
} 
falar mesmo em um entusiasmo do setor com base em iniciativas relevantes que dão retorno satisfatório. Em função deste movimento, é de se supor a existência concreta de um público leitor e consumidor para estas obras. Afinal, as editoras não lançam tantos desses produtos para que fiquem acumulando poeira nas estantes de livrarias. Resta aguardar que o meio acadêmico corresponda a estas tendências, aproveitando cada vez mais este afluxo para dinamizar os estudos nas diversas áreas do conhecimento, para ir buscar no cotidiano encadernado a matéria para reflexões e descobertas incessantes. (SIMON, 2004, p. 10)

Observamos que todos os melindres referentes ao status da crônica como texto literário, de menor ou maior envergadura, e sua presença num suporte como o livro, se referendam muitas vezes pelo conteúdo/assunto perecível que encontramos escrito no gênero, bem como de seu veículo principal e de origem, o jornal. Mas, como observa Coutinho (2007, p. 305), "O fato de ser divulgado em jornal não implica em desvalia literária do gênero [...] A crônica é na essência uma forma de arte, arte da palavra, a que se liga forte dose de lirismo".

\subsection{A CRONÍSTICA BRASILEIRA DE RUBEM BRAGA}

Muitos são os cronistas que fazem parte do rol literário brasileiro e muitos são seus estilos. Coutinho (1971) identifica cinco tipologias de crônicas brasileiras: a narrativa, a metafísica, a poema-em-prosa, a crônica-comentário e a crônica-informação. A cronística rubembraguiana se encaixa na do tipo poema-em-prosa, haja vista seu conteúdo lírico "[...] poesia comunicativa a brotar da prosa espontânea" (CASTELLO, 1964, p. 141).

Em meio a palavras enxutas, diretas, simples, Braga expõe sua sutil ironia e cético humor através de um estilo humilde, refinado e sem exageros. Essa aparente simplicidade de escrita que aproxima o leitor do texto, paradoxalmente torna esse texto difícil de ser analisado criticamente. Segundo Arrigucci (1999, p. 148), "Rubem Braga é um autor de acesso fácil e imediato para quem lê, mas extraordinariamente difícil para quem quer falar criticamente do que leu".

Quase que exclusivamente cronista, com exceção de um livro de poemas intitulado simplesmente de Livro de Versos (1980), Braga torna-se um ícone do gênero não pela exclusividade em si, nem pelo volume de produção (cerca de 15 mil crônicas), mas pela robustez, grandiosidade e singularidade da obra, por elevar o status do gênero crônica. Sobre esse aspecto, Castello (1964, p. 143) observa que "[...] podemos dizer que o Sr. Rubem Braga consegui superar as limitações do gênero do ponto de vista artístico, dando-lhe êsse sentido de permanência".

Quanto ao estilo, à recepção da obra e à transcendência da mera informação, Chagas e Rio Doce (2013) observam que a crônica rubembraguiana "Serve o leitor de uma narrativa em primeira pessoa, que lembra a tradição oral do contador de histórias, amplifica a mensagem que deseja passar, desloca-a do campo informativo e, assim, dá margem a diversas interpretações." Afrânio Coutinho (1971, p. 120) assim resume a técnica e o talento do cronista-poeta capixaba:

De tôdas as figuras de cronistas contemporâneos aquela que mais atrai a admiração é Rubem Braga, o escritor que entra para a história literária exclusivamente como cronista. Sua técnica é dar pouco aprêço aos fatos do mundo real e muita vez os escolhe como simples pretexto para a divagação pessoal. É seguramente o mais subjetivo dos cronistas brasileiros. E o mais lírico. Muitas de suas crônicas são poemas em prosa. Apresentando a originalidade de uma imaginação poética e irradia, Rubem Braga, em seu lirismo, escreve sem ornatos e alcança às vezes a simplicidade clássica, numa língua despojada, melodiosa, direta. 
Como seria o processo de escrita de Braga? Ao lermos a biografia do cronista, escrita por Castelo (1996), vemos uma descrição da difícil e trabalhosa tarefa de escrever. O biógrafo chega a afirmar que esta era uma "atividade torturante" para Braga, e nos descreve a seguinte cena:

O Urso se levanta, ronda pela sala, ajeita uma moldura fora de linha, dá voltas, remexe nas plantas, assobia. Por fim, volta à rede e ao caderno para anotar meia dúzia de linhas. Agora podemos aproveitar que ele se levantou para nova volta pelo jardim e dar uma espiada em seus originais. A escrita é suja, remendada, bordada por garranchos e riscos grosseiros. Há palavras dependuradas nas margens, palavras empilhadas sobre palavras, anotações transversas, comentários rasantes para si mesmo, do tipo: "Está péssimo", "Reescrever correndo", "Cortar". O cronista é impiedoso consigo mesmo, e é dessa rigidez e impaciência que nasce o texto elegante e fluente que tanto gostamos de ler. (CASTELO,1996, p. 70),

Essa descrição de seu fazer literário instiga, principalmente, o crítico genético, que, através dessa "escrita suja, remendada, bordada por garranchos e riscos grosseiros", encontraria um rico caminho para refletir acerca do escrever rubembraguiano.

Outra informação que interessa ao crítico textual da obra do autor, diz respeito às prováveis interferências não-autorais que um texto de Braga possa ter sofrido, desde o editor do jornal ao do livro. De acordo com uma reportagem referente a sua morte (revista Veja, de 26 de dezembro de 1990, páginas 106-107), dentre as particularidades de Rubem Braga havia a de não ter ciúmes de suas crônicas.Vejamos:

[...] não tinha lá muito ciúmes de seus escritos. Se um editor de jornal, ao receber uma crônica, ligasse para ele para negociar alguma modificação no texto - um par de vírgulas fora do lugar, uma frase de compreensão difícil -, sua resposta era sempre mesma: "Mexa como quiser, faça o que achar". Era um escritor disposto a incorporar qualquer recurso que lhe fosse sugerido, até porque não havia meio de contaminar suas crônicas. Por escrever quase exclusivamente em jornais, Braga não achava que tinha um nome a zelar, uma reputação ou mesmo uma obra. Ele não se pautava por qualquer desses conceitos abstratos que costumam servir de escudos para escritores de muita pompa e pouca prosa. (VEJA, 1990, p. 107)

Supomos que esse "desapego" a sua obra seja provindo tanto da segurança em seu traço original, como colocado na reportagem, como pela leveza que, de certa forma, aparentava dar a seus escritos ao classificá-los como subliteratura. Um ano antes de falecer, passados mais de 60 anos de escrita cotidiana, Rubem Braga conceitua, a seu modo, o gênero crônica em sua coluna da Revista Nacional. Vejamos:

Respondo que a crônica não é literatura, e sim subproduto da literatura, que a crônica está fora do propósito do jornal. A crônica é subliteratura que o cronista usa para desabafar perante os leitores. O cronista é um desajustado emocional que desabafa com os leitores, sem dar a eles a oportunidade para que rebatam qualquer afirmativa publicada. A única informação que a crônica transmite é a de que o respectivo autor sofre de neurose profunda e precisa desoprimir-se. Tal informação, de cunho puramente pessoal, não interessa ao público, e portanto deve ser suprimida. (In: CASTELO, 1996, p. 70). 
Despretensioso autor, próprio de um gênero despretensioso como é a crônica. Sua escrita é sua vida, tarefa árdua, mas essencial. Braga escreve até seu último dia. Poucas horas antes de morrer, ele envia seu último texto para a redação da Revista Nacional. Falecendo aos 20 dias do mês de dezembro do ano de 1990, na cidade do Rio de Janeiro.

\subsubsection{A crônica rubembraguiana em livros didáticos}

Ao folhearmos as páginas de livros didáticos de Língua Portuguesa, principalmente das séries do segundo ciclo do Ensino Fundamental, percebemos a constante e maciça presença de gêneros textuais como contos e crônicas. A presença da crônica em livros didáticos pode ser justificada por algumas razões, tais como, ser um texto de extensão curta e possuir linguagem mais simples e próxima da oralidade. Podemos supor que esses sejam alguns dos fatores que colocam este gênero nas salas de aula, propiciando seu acesso desde cedo. Bender (1993, p. 44) observa que "[...] a crônica, principalmente por ser tão difundida nos livros didáticos, acaba sendo a principal fonte de texto literário para a maioria dos nossos jovens, quando não a única, pelo menos no $1^{\circ}$ grau." Sem dúvidas, grande parte do contato com leitura e escrita no Ensino Fundamental se deu e se dá através do gênero crônica.

Autores como Carlos Drummond de Andrade, Luís Fernando Veríssimo, Fernando Sabino e, é claro, Rubem Braga são presenças frequentes nas páginas didáticas. Sobre esse aspecto, destacamos a fala do editor Jiro Takahashi, criador da coleção Para gostar de ler, quando, em uma conversa com Affonso Romano de Santana, discutiam acerca do frequente uso das crônicas de Rubem Braga em sala de aula, vejamos:

Na metade dos anos 70, a Editora Ática já tinha duas coleções bem consolidadas para o público escolar. Um dia o escritor Affonso Romano de Sant'Anna telefonou para o editor Jiro Takahashi para conversar sobre o cronista Rubem Braga. "Um dos pontos era tentar entender o motivo de ele ser tão usado nas salas de aula, mas isso não se refletia na divulgação e venda de seus livros de crônicas nas livrarias", explica Takahashi. (On line, 2014. Grifo nosso)

Bender (1993, p. 49) também observa essa frequência e a justifica pelo pioneirismo da obra de Braga "Por ter sido pioneiro da crônica contemporânea, difícil um texto seu não ter se tornado antológico e não pertencer a livro didático." Partindo desse pressuposto, vemos como acertada a escolha do gênero textual e do autor para a presente pesquisa.

\section{FILOLOGIA EM PÁGINAS DIDÁTICAS: O CASO DA CRÔNICA ELA TEM ALMA DE POMBA}

De acordo com discussões mais recentes acerca do ensino de Língua Portuguesa, atestamos que o papel do texto, em qualquer gênero, ganha total importância, haja vista as aulas de língua encontrarem-se alicerçadas na leitura, análise e produção de texto. Sendo assim, temos o texto como um dos pilares do ensino e principal meio de divulgação da informação e formação do conhecimento. Segundo Alves (2016, p. 61 - 62), 
[...] pensar em textos é automaticamente pensar em trabalhar com a leitura e a escrita e, consequentemente, trabalhar, através deles com a constituição e formação de sujeitos reflexivos e atuantes no mundo. Ao pensarmos em livros didáticos (e de modo correlato nos diversos tipos e gêneros de textos que o integram) também devemos atentar para a forma como são transmitidos.

Quando falamos de estudos filológicos, na vertente da Crítica Textual, voltados para o ensino, desembocaremos na análise de textos/materiais didáticos (livros, apostilas, módulos, etc.). Além da análise da transmissão do texto, os estudos filológicos podem contribuir para a produção de materiais didáticos mais apropriados, como ressalta Alves (2016, p. 62) "Assim, podemos encarar a Crítica Textual como agente colaborador dos estudos desenvolvidos sobre materiais didáticos dentro da Linguística Aplicada".

Dentro dessa perspectiva e ao observarmos o histórico de pesquisas que relacionam a Filologia com esse campo, nos deparamos com o trabalho empreendido por Marlene Mendes e seus orientandos, desenvolvido no Departamento de Linguística e Filologia da Universidade Federal Fluminense, na primeira metade da década de 1980. $\mathrm{O}$ artigo $A$ fidedignidade dos textos nos livros didáticos de Comunicação e Expressão no Brasil, de 1986, apresenta o resultado desse projeto que tinha por objetivo verificar como os textos literários "[...] eram tratados pelos autores de livros didáticos de Comunicação e Expressão" (MENDES, 1986, p. 163). A autora e seu grupo selecionaram 36 livros$^{2}$ e deles retiraram, aleatoriamente, 150 textos (entre versos e prosas) e fizeram suas análises verificando aspectos concernentes ao campo da Crítica Textual. Através dessas análises, puderam identificar e levantar tipos de alterações que ocorriam e que implicavam na questão da fidedignidade do texto. Aspectos como supressões, acréscimos de palavras e/ou expressões, modificações referentes a pessoas e tempos verbais, pontuações, entre outros, foram destacados.

Dos anos oitenta pra cá, algumas foram as investidas de pesquisas nessa linha, tais como as empreendidas por Sandro Drumond Alves e seus orientandos, cujo foco passa pela análise de textos em livros didáticos de espanhol e reflexões acerca da importância da Crítica Textual no currículo dos Cursos de Letras. Célia Marques Telles, no artigo intitulado Que textos são oferecidos aos estudantes?, faz referência ao assunto, também citando o trabalho de Mendes (1986). Mais atualmente temos a dissertação de Virgínia Maria Baldow, A genuinidade de textos literários em livros didáticos de língua portuguesa (UEFS, 2013), voltada para uma análise dessa relação de fidedignidade e o ensino de literatura.

Tomando como exemplo essas pesquisas, realizamos neste trabalho um exercício de cotejo entre testemunhos. Para uma melhor compreensão desse confronto, faz-se necessário um esclarecimento referente aos três tipos que foram comparados e analisados. O primeiro testemunho, o Texto Didático (TD), como a própria denominação revela, trata-se do texto encontrado transcrito no livro didático. O segundo testemunho é o que chamamos de Texto Base (TB), ou seja, o texto que consideramos como o fidedigno, neste caso, a última edição publicada em vida do autor. $O$ terceiro testemunho, denominado Texto Indicado como Referência (TIR), refere-se à referência indicada pelo próprio livro didático (quando existe).

\footnotetext{
${ }^{2}$ Destacamos os anos e séries elecandos no trabalho de Mendes (1985). Os testemunhos foram coletados em 36 livros (4 de 1978, 1 de 1979, 1 de 1980,4 de 1981, 3 de 1982, 10 de 1983, 1 de 1984, 12 livros não indicam ano de publicação), de $1^{a}$ série à $8^{\mathrm{a}}$ série, ou seja, todas as séries que correspondem atualmente ao ensino fundamental $\left(1^{\circ}\right.$ e $2^{\circ}$ ciclos $)$
} 
Partindo da comparação entre estes tipos de testemunhos, podemos levantar questões e/ou explicações referentes aos motivos das variações, bem como as implicações que possam ocorrer numa análise de cunho crítico-literário.

Para a análise da crônica Ela tem alma de pomba, escolhemos como Texto Base a $7^{\mathrm{a}}$ edição do livro "200 Crônicas Escolhidas", datada de 1988. Vale ressaltar que essa crônica teve sua primeira publicação em livro na primeira edição do "200 Crônicas Escolhidas", de 1977. Essa informação fica clara na nota que o autor escreve no início da primeira edição e que se repete nas outras, vejamos: "Tirante as duas últimas, as crônicas deste volume são recolhidas entre as de meus livros. A primeira escolha foi feita por Fernando Sabino, mas eu troquei uma ou outra, levado por algum motivo, às vezes sentimental. RB" (BRAGA, 1977). Ela tem alma de pomba é a penúltima crônica do livro, sendo assim, faz parte dessa pequena exceção observada por autor. Apuramos que essa crônica foi antes publicada na Revista Veja, Edição 447, de 30 de março de 1977, página 9, fazendo parte de uma propaganda da empresa de eletrônicos Sharp. No "200 Crônicas Escolhidas", o autor indica que a crônica foi escrita em abril de 1977. Por ter feito algumas pequenas alterações do texto da revista para o publicado em livro, encontramos justificativa para a diferença de um mês.

Em páginas didáticas foram encontradas, até o presente ponto da pesquisa, 7 versões/transcrições dessa crônica (2 da década de 1980, 3 da década de 1990 e 2 da década de 2000). Dessas 7 transcrições, 3 apresentam divergências e variações substanciais. À guisa de exemplificação, destacamos o testemunho do livro Encontro e reencontro em Lingua Portuguesa: reflexão e ação de Marilda Prates (1998). Apesar da autoria explícita, tomaremos como base o conceito de autor do livro didático como uma entidade coletiva, desde editor, diagramador, revisor, ou seja, uma equipe de elaboração (Ver. BALDOW, 2013). Apresentamos este cotejo de duas formas: a primeira através de uma tabela com os três testemunhos dispostos um ao lado do outro, e a segunda aparece o Texto Didático com notas abaixo destacando as variantes encontradas.

\begin{tabular}{|c|c|c|}
\hline TEXTO DIDÁTICO & TEXTO BASE & $\begin{array}{l}\text { TEXTO INDICADO } \\
\text { COMO REFERÊNCIA }\end{array}$ \\
\hline $\begin{array}{l}\text { PRATES, Marilda. Encontro e } \\
\text { reencontro em Língua } \\
\text { Portuguesa: reflexão e ação. } 5^{a} \\
\text { série. São Paulo: Moderna, } \\
\text { 1998. }\end{array}$ & $\begin{array}{l}\text { BRAGA, Rubem. } 200 \text { crônicas } \\
\text { escolhidas. Rio de Janeiro, } 7 \text { ed., } \\
\text { Record, } 1988\end{array}$ & $\begin{array}{l}\text { Revista Veja, Edição número } \\
\text { 447, de } 30 \text { de março de } 1977 \text {, } \\
\text { página } 9 .\end{array}$ \\
\hline $\begin{array}{l}\text { Ela tem alma de pomba } \\
\text { Que a televisão prejudica o } \\
\text { movimento da pracinha, não há } \\
\text { dúvida. } \\
\text { Sete horas da noite era } \\
\text { hora de uma pessoa acabar de } \\
\text { jantar, dar uma volta pela praça } \\
\text { e depois pegar a sessão das oito } \\
\text { no cinema. }\end{array}$ & $\begin{array}{l}\text { Ela tem alma de pomba } \\
\text { Que a televisão prejudica o } \\
\text { movimento da pracinha Jerônimo } \\
\text { Monteiro, em todos os } \\
\text { Cachoeiros de Itapemirim, não há } \\
\text { dúvida. Sete horas da noite era } \\
\text { hora de uma pessoa acabar de } \\
\text { jantar, dar uma volta pela praça } \\
\text { para depois pegar uma sessão das } \\
8 \text { no cinema. Agora todo mundo }\end{array}$ & $\begin{array}{l}\text { Ela tem alma de pomba } \\
\text { Que a televisão prejudica o } \\
\text { movimento da pracinha } \\
\text { Jerônimo Monteiro, em todos } \\
\text { os Cachoeiros de Itapemirim, } \\
\text { não há dúvida. } \\
\text { Sete horas da noite era hora de } \\
\text { uma pessoa acabar de jantar, dar } \\
\text { uma volta pela praça para }\end{array}$ \\
\hline
\end{tabular}


Agora todo mundo fica em casa vendo uma novela, depois outra novela.

Que a televisão prejudica a leitura de livros, também não há dúvida. Eu mesmo confesso que lia mais quando não tinha televisão.

Rádio, a gente pode ouvir baixinho, enquanto está lendo um livro. Televisão é incompatível com livro - e com tudo mais nesta vida, inclusive boa conversa.

Também acho que a televisão paralisa a criança numa cadeira mais que o desejável. $\mathrm{O}$ menino fica ali parado, vendo e ouvindo, em vez de sair, chutar uma bola, brincar de bandido, inventar uma história qualquer para fazer. Por exemplo: quebrar um braço.

Só não acredito que televisão seja "máquina de fazer doido".

Até acho que é o contrário, ou quase o contrário: é máquina de amansar doido, fazer doido dormir.

Quando você cita um inconveniente da televisão, uma boa observação é que não existe nenhum aparelho de TV, em cores ou em preto e branco, sem um botão para desligar.

Mas quando um pai de família o utiliza, isso pode produzir o ódio e rancor no peito das crianças, e até de outros adultos. Se o apartamento é pequeno, a família é grande, e a TV é uma só, então a sua tendência é para ser um fator de rixas intestinas...

- Agora você agarra nessa porcaria de futebol...

- Mas, francamente, você não tem vergonha de fica em casa vendo uma novela, depois outra novela.

O futebol também pode ser prejudicado. Quem vai ver um jogo do Estrela do Norte F.C., se pode ficar tomando cervejinha e assistindo a um bom Fla-Flu, ou a um Inter x Cruzeiro, ou qualquer coisa assim?

Que a televisão prejudica a leitura de livros, também não há dúvida. Eu mesmo confesso que lia mais quando não tinha televisão. Rádio, a gente pode ouvir baixinho, enquanto está lendo um livro. Televisão é incompatível com livro - e com tudo mais nesta vida, inclusive a boa conversa, até o making love.

Também acho que a televisão paralisa a criança numa cadeira mais do que o desejável. $\mathrm{O}$ menino fica ali parado, vendo e ouvindo, em vez de sair por aí, chutar uma bola, brincar de bandido, inventar uma besteira qualquer para fazer.

Só não acredito que televisão seja máquina de fazer doido. Até acho que é o contrário, ou quase o contrário: é máquina de amansar doido, distrair doido, acalmar, fazer doido dormir.

Quando você cita um inconveniente da televisão, uma boa observação que se pode fazer é que não existe nenhum aparelho de TV, a cores ou em preto e branco, sem um botão para desligar. Mas quando um pai de família o utiliza, isso pode produzir o ódio e rancor no peito das crianças e até de outros adultos.

Quando o apartamento é pequeno, a família é grande, e a TV é só uma - então sua depois pegar a sessão das 8 no cinema.

Agora todo mundo fica em casa vendo uma novela, depois outra novela.

O futebol também pode ser prejudicado. Quem vai ver um jogo do Cachoeiro F. C. com o Estrela do Norte F.C., se pode ficar tomando cervejinha e assistindo a um bom Fla-Flu, ou a um Internacional x Cruzeiro, ou qualquer coisa assim?

Que a televisão prejudica a leitura de livros, também não há dúvida. Eu mesmo confesso que lia mais quando não tinha televisão.

Rádio, a gente pode ouvir baixinho, enquanto está lendo um livro. Televisão é incompatível com livro - e com tudo mais nesta vida, inclusive a boa conversa, até o making love.

Tabém acho que a televisão paralisa a criança numa cadeira mais do que o desejável. $\mathrm{O}$ menino fica ali parado, vendo e ouvindo, em vez de sair por aí, chutar uma bola, brincar de bandido, inventar uma besteira qualquer para fazer. Por exemplo: quebrar um braço.

Só não acredito que televisão seja "máquina de fazer doido".

Até acho que é o contrário, ou quase o contrário: é máquina de amansar doido, distrair doido, acalmar, fazer doido dormir.

Quando você cita um inconveniente da televisão, uma 
acompanhar essa besteira de novela?

crianças!

- Não sou eu, são as

- Crianças, já para a cama!

Mas muito lhe será perdoado, à TV, pela sua ajuda aos doentes, aos velhos, aos solitários. Na grande cidade num apartamento pequeno e solitário, o grande consolo, a grande companhia.

A corujinha da madrugada não é apenas a companheira de gente importante, é a grande amiga da pessoa desimportante e só, da mulher velha, do homem doente... É a amiga dos entrevados, dos abandonados, dos que a vida esqueceu num canto... ou dos que no meio da noite sofrem o assalto de dúvidas e melancolias... mãe que espera filho, mulher que espera marido... homem arrasado que espera que a noite passe, que a noite passe... tendência é para ser um fator de rixas intestinas.

- Agora você se agarra nessa porcaria de futebol...

- Mas, francamente, você não tem vergonha de acompanhar essa besteira de novela?

- Não sou eu não, são as crianças!

- Crianças, para a cama!

Mas muito lhe será perdoado, à TV, pela sua ajuda aos doentes, aos velhos, aos solitários. $\mathrm{Na}$ grande cidade - num apartamentinho de quarto e sala, num casebre de subúrbio, numa orgulhosa mansão - a criatura solitária tem nela a grande distração, o grande consolo, a grande companhia. Ela instala dentro de sua toca humilde o tumulto e o frêmito de mil vidas, a emoção, o suspense, a fascinação dos dramas do mundo.

A corujinha da madrugada não é apenas a companheira de gente importante, é a grande amiga da pessoa desimportante e só, da mulher velha, do homem doente... É a amiga dos entrevados, dos abandonados, dos que a vida esqueceu para um canto... ou dos que estão parados, paralisados, no estupor de alguma desgraça... ou que no meio da noite sofrem o assalto de dúvidas e melancolias... mãe que espera filho, mulher que espera marido... homem arrasado que espera que a noite passe, que a noite passe, que a noite passe... boa observação que se pode fazer é que não existe nenhum aparelho de TV, em cores ou em preto e branco, sem um botão para desligar.

Mas quando um pai de família o utiliza, isso pode produzir o ódio e rancor no peito das crianças, e até de outros adultos.

Se o apartamento é pequeno, a família é grande, e a TV é só uma - então sua tendência é para ser um fator de rixas intestinas.

- Agora você se agarra nessa porcaria de futebol...

- Mas, francamente, você não tem vergonha de acompanhar essa besteira dessa novela?

- Não sou eu não, são as crianças!

- Crianças, para a cama!

Mas muito lhe será perdoado, à TV, pela sua ajuda aos doentes, aos velhos, aos solitários. $\mathrm{Na}$ grande cidade - num apartamentinho de quarto e sala, num casebre de subúrbio, numa orgulhosa mansão a criatura solitária tem nela a grande distração, o grande consolo, a grande companhia. Ela instala dentro de sua toca humilde o tumulto e o frêmito de mil vidas, a emoção, o suspense, a fascinação dos dramas do mundo.

A corujinha da madrugada não é apenas a companheira de gente importante, é a grande amiga da pessoa desimportante e só, da mulher velha, do homem doente... É a amiga dos entrevados, dos abandonados, dos que a vida esqueceu para 


\begin{tabular}{|l|l|l|}
\hline \multirow{2}{*}{} & $\begin{array}{l}\text { um canto... ou dos que estão } \\
\text { parados, paralisados, no } \\
\text { estupor de alguma desgraça... } \\
\text { ou que no meio da noite } \\
\text { sofrem o assalto de dúvidas e } \\
\text { melancolias... mãe que espera } \\
\text { filho, mulher que espera } \\
\text { marido... homem arrasado que } \\
\text { espera que a noite passe, que a } \\
\text { noite passe, que a noite passe... }\end{array}$ \\
\hline
\end{tabular}

PRATES, Marilda. Encontro e reencontro em Língua Portuguesa: reflexão e ação. $5^{a}$ série. São Paulo: Moderna, 1998.

Ela tem alma de pomba

Que a televisão prejudica o movimento da pracinha, (1) não há dúvida.

Sete horas da noite era hora de uma pessoa acabar de jantar, dar uma volta pela praça e depois pegar a sessão das oito (2) no cinema.

(3) Agora todo mundo fica em casa vendo uma novela, depois outra novela.

Que a televisão prejudica a leitura de livros, também não há dúvida. Eu mesmo confesso que lia mais quando não tinha televisão.

Rádio, a gente pode ouvir baixinho, enquanto está lendo um livro. Televisão é incompatível com livro - e com tudo mais nesta vida, inclusive boa conversa. (4)

Também acho que a televisão paralisa a criança numa cadeira mais que o desejável. $\mathrm{O}$ menino fica ali parado, vendo e ouvindo, em vez de sair, chutar uma bola, brincar de bandido, inventar uma história qualquer para fazer. Por exemplo: quebrar um braço. ${ }^{(5)}$

Só não acredito que televisão seja "máquina de fazer doido".

Até acho que é o contrário, ou quase o contrário: é máquina de amansar doido, fazer doido dormir.(的)
(1) TB/ TIR: “Que a televisão prejudica o movimento da pracinha Jerônimo Monteiro, em todos os Cachoeiros de Itapemirim, não há dúvida."

(2) TB/ TIR: “[...] depois pegar a sessão das $\mathbf{8}$ no cinema."

(3) TB: "O futebol também pode ser prejudicado. Quem vai ver um jogo do Estrela do Norte F.C., se pode ficar tomando cervejinha $\mathrm{e}$ assistindo a um bom FlaFlu, ou a um Inter $x$ Cruzeiro, ou qualquer coisa assim?"

TIR: "O futebol também pode ser prejudicado. Quem vai ver um jogo do Cachoeiro F. C. com o Estrela do Norte F.C., se pode ficar tomando cervejinha e assistindo a um bom Fla-Flu, ou a um Internacional x Cruzeiro, ou qualquer coisa assim?"

(4) TB/ TIR: “Televisão é incompatível com livro - e com tudo mais nesta vida, 
Quando você cita um inconveniente da televisão, uma boa observação é que não existe nenhum aparelho de TV, em cores ou em preto e branco, sem um botão para desligar.

Mas quando um pai de família o utiliza, isso pode produzir o ódio e rancor no peito das crianças, e até de outros adultos. Se o apartamento é pequeno, a família é grande, e a TV é uma só, então a sua tendência é para ser um fator de rixas intestinas... futebol...

- Agora você agarra nessa porcaria de

- Mas, francamente, você não tem vergonha de acompanhar essa besteira de novela?

- Não sou eu, são as crianças!

- Crianças, já (7) para a cama!

Mas muito lhe será perdoado, à TV, pela sua ajuda aos doentes, aos velhos, aos solitários. $\mathrm{Na}$ grande cidade - num apartamento (8) pequeno e solitário, o grande consolo, a grande companhia. (9)

A corujinha da madrugada não é apenas a companheira de gente importante, é a grande amiga da pessoa desimportante e só, da mulher velha, do homem doente... É a amiga dos entrevados, dos abandonados, dos que a vida esqueceu (10) num canto (11)... ou dos que no meio da noite sofrem o assalto de dúvidas e melancolias... mãe que espera filho, mulher que espera marido... homem arrasado que espera que a noite passe, ${ }^{(12)}$ que a noite passe... inclusive a boa conversa, até o making love."

(5) TB: "O menino fica ali parado, vendo e ouvindo, em vez de sair por aí, chutar uma bola, brincar de bandido, inventar uma besteira qualquer para fazer ø”

(6) TB/ TIR: “Até acho que é o contrário, ou quase o contrário: é máquina de amansar doido, distrair doido, acalmar, fazer doido dormir."

(7) TB/ TIR: “- Crianças, ø para a cama!"

(8) TB/ TIR:"Na grande cidade - num apartamentinho de quarto e sala, num casebre de subúrbio, numa orgulhosa mansão a criatura solitária tem nela a grande distração, o grande consolo, a grande companhia. Ela instala dentro de sua toca humilde o tumulto e o frêmito de mil vidas, a emoção, o suspense, a fascinação dos dramas do mundo."

(9) TB/ TIR: Ela instala dentro de sua toca humilde o tumulto e o frêmito de mil vidas, a emoção, o suspense, a fascinação dos dramas do mundo."

(10) TB/ TIR: “[...] dos que a vida esqueceu para um canto..."

(11) TB/ TIR: “[...] ou dos que estão parados, paralisados, no estupor de alguma desgraça... ou que no meio 
da noite sofrem o assalto de dúvidas e melancolias..."

(12) TB/ TIR: "homem arrasado que espera que a noite passe, que a noite passe, que a noite passe..."

(13) TB:" Abril, 1977"

Como vimos, a crônica Ela tem alma de pomba, encontrada nas páginas 229-230 do livro Encontro e reencontro em Língua Portuguesa: reflexão e ação - $5^{\text {a }}$ série, apresenta diversas divergências em relação ao texto indicado como referência pelo livro didático, bem como com o texto base escolhido nesta pesquisa.

Inicialmente, destacamos algumas observações referentes ao TIR, ou seja, o texto indicado pelo livro didático como fonte. Ao final da crônica nos é apresentada a seguinte referência "Rubem Braga, Revista Veja, n 375, jul. 1976". Ao pesquisarmos essa referência, averiguamos que o número da revista indicado era, na realidade, do dia 12 de novembro do ano de 1975 e não havia nenhuma crônica do autor nessa edição. Também averiguamos a edição do mês de julho do ano de 1976, nada foi encontrado nesse exemplar. Ao voltarmos para o TB percebemos que a data indicada ao final da crônica pelo autor era Abril de 1977. Voltamos aos arquivos da revista Veja e, seguindo a referência da mesma crônica de outro livro didático, chegamos ao que consideramos a indicação correta do TIR: Revista Veja, Edição 447, de 30 de março de 1977, página 9. Pudemos atestar essa referência ao cotejarmos os testemunhos.

Outro fato que deve ser levantado diz respeito a um outro testemunho dessa mesma crônica, do livro didático Português: educação e o desenvolvimento do senso crítico", de Gianini et ali, datado do ano de 1988. Ao cotejarmos as crônicas apresentadas nos dois livros didáticos, dos anos de 1988 e 1998, verificamos a quase total fidelidade, com exceção de uma única divergência (referente ao modo de um verbo). Sendo assim, podemos levantar a hipótese de que o livro de Prates (1998) tenha tomado por base o livro de Gianini et ali (1988) ou outro livro. Não encontramos, até o momento, nenhuma relação entre esses dois livros didáticos. Mesmo assim, levantamos a hipótese de que a referência indicada possa ter sido "inventada" ou equivocadamente colocada pelo livro de 1988 e o livro de 1998 simplesmente copiado, sem indicar a real referência. Portanto, tendo em vista as evidências de que o real TIR seja a revista Veja de Novembro de 1977, assim o escolhemos para a realização do cotejo e suas análises.

Quanto às variações encontradas na crônica, pudemos observar que o TD apresenta-se deveras multilado. Seja com o intuito de resumir ou de simplificar, como nos excertos 1, 3, 4, 6, $9,11,12$, ou acrescentar algo com o intuito de enfatizar, como no caso 7 , verificamos que não há por parte da autoria do LD uma simples preocupação em indicar a modificação. A total retirada de um parágrafo é passada de forma natural, exemplo 3. Ao que parece, utilizaram o texto literário como posse sua e sentiram-se com total liberdade para realizarem qualquer modificação, mesmo que esta possa descaracterizar o texto, o gênero e o autor.

Como vimos, há também variações entre o TB eo TIR, como observado nos excertos 3 e 5 , revelando as modificações que o autor da crônica, Rubem Braga, poderia fazer ao passar o 
texto antes publicado em algum veículo de comunicação mais efêmero, como o jornal ou revista, para um mais perene, como é o livro. Como esperado, cotejo do TB com o TD corrobora as variações entre TIR e TD.

\section{CONSIDERAÇÕES FINAIS}

Através deste breve exercício de cotejo e análise, identificamos os diversos tipos de variações que podem ocorrer no processo de transmissão de um texto literário para o veículo didático, neste caso, um livro. Desde omissões, a substituições, acréscimos a reelaborações. Cada uma dessas interferências, em menor ou maior grau, altera o sentido do texto implicando na análise de nível crítico-literário. A partir da análise dessas variantes, juntamente com aspectos outros presentes no livro didático, podemos levantar hipóteses acerca do que causou ou motivou cada uma dessas alterações. Entretanto, essas informações ficarão para um próximo texto, haja vista este trabalho se encontrar em curso. De antemão, podemos atestar que o campo que une a metodologia filológica com o campo do ensino e da literatura muito tem a crescer.

\section{REFERÊNCIAS}

A HISTÓRIA da coleção Para gostar de ler. Disponível em: https://rubem.wordpress.com/2014/05/29/a-historia-da-colecao-para-gostar-de-ler/ Acesso em 09 mar. 2018

ALVES, Sandro Marcio Drumond. A Crítica Textual na formação inicial docente: repensando o currículo a partir do livro didático. In: OLIVEIRA, Luiz Eduardo; MENESES, Jonatas Silva (orgs.) (Re)pensando as licenciaturas. São Cristovão: Editora UFS, 2016.

ARRIGUCCI JR, Davi. Enigma e comentário: ensaios sobre literatura e experiência. São Paulo: Companhia das Letras, 1987.

. Outros achados e perdidos. São Paulo: Companhia das Letras, 1999.

BALDOW, Virgínia M. F. S. A genuinidade de textos literários em livros didáticos de língua portuguesa. Feira de Santana - BA, 2013. Dissertação (Mestrado em Literatura e Diversidade Cultural) Universidade Estadual de Feira de Santana, Departamento de Letras e Artes, Programa de Pós Graduação em Literatura e Diversidade Cultural, 2013.

BENDER, Flora Christina. Teoria. In: LAURITO, Ilka Brunhilde; BENDER, Flora Christina. Crônica: história, teoria e prática. São Paulo: Scipione, 1993.

BRAGA, Rubem. 200 crônicas escolbidas. Rio de Janeiro: Record, 1988.

CANDIDO, Antônio. A vida ao rés-do-chão. In: CANDIDO, Antonio [et al.]. Crônica: o gênero, sua fixação e suas transformações no Brasil. Campinas, SP: Editora da UNICAMP; Rio de Janeiro: Fundação Casa de Rui Barbosa, 1992.

CASTELLO, José Aderaldo. Método e interpretação. São Paulo: Conselho Estadual de Cultura. Comissão Literatura, 1964.

CASTELLO, José. Na cobertura do Braga. $3^{\text {a }}$ ed. Rio de janeiro: José Olympio Editora, 2013 
CARVALHO, Marco Antonio de. Rubem Braga: um cigano fažendeiro do ar. São Paulo: Globo, 2007.

CHAGAS, Adriano; RIO DOCE, Cláudia Camardella. Imagens suprarreais para Um pé de milho, de Rubem Braga. Revista Estação Literária. Londrina, Volume 11, p. 285-296, jul. 2013.

COUTINHO, Afrânio (dir.). A literatura no Brasil. Vol. IV. 19 ed. Rio de Janeiro: Sul Americana, 1971.

LAURITO, Ilka Brunhilde. História. In: LAURITO, Ilka Brunhilde; BENDER, Flora Christina. Crônica: história teoria e prática. São Paulo: Scipione, 1993.

MENDES, Marlene C. Gomes. A fidedignidade dos textos nos livros didáticos de Comunicação e Expressão no Brasil. In: I Encontro de Crítica Textual, 1985, São Paulo. Anais do I Encontro de Crítica Textual: o manuscrito moderno e as edições. São Paulo: EDUSP, 1986. p. 163-174

PRATES, Marilda. Encontro e reencontro em Lingua Portuguesa: reflexão e ação. $5^{a}$ série. São Paulo:

Moderna, 1998.

REVERBEL, Carlos. Introdução. In: BRAGA, Rubem. 1939, um episódio em Porto Alegre. Rio de Janeiro: Record, 2002.

SÁ, Jorge de. A crônica. $4^{a}$ ed. Série Princípios. São Paulo: Editora Ática, 1992

SIMON, Luis Carlos Santos. O cotidiano encadernado: a crônica no livro. Anais do I Seminário Brasileiro sobre o Livro e História Editorial. FCRB - UFF/PPGCOM- UFF/LIHED. Rio de Janeiro, 2004.2 Disponível em: <http://www.livroehistoriaeditorial.pro.br/pdf/luizcarlossimon.pdf> Acesso em: 05 jan. 2018.

REVISTA VEJA - Edição 447 de 30 de março de 1977, página 9 Disponível em: $<$ https://acervo.veja.abril.com.br/index.html\#/edition/34104?page=1\&section=1 > Acesso em 28 jul. 2017

TELLES, Célia M. Que textos são oferecidos aos estudantes?. In: Estudos Filológicos: Linguistica Românica e Crítica Textual. ALMEIDA, et al (org.) Salvador: EDUFBA, 2016. 